\title{
Sustainability is Important Part of the Identity in the Dimension of Regionalism Architecture
}

ARTICLE · MARCH 2015

DOI: 10.4028/www.scientific.net/AMM.747.145

READS

16

3 AUTHORS:

Q Maria Hidayatun

Petra Christian University

12 PUBLICATIONS 1 CITATION

SEE PROFILE

Murni Rachmawati

Institut Teknologi Sepuluh Nopember

9 PUBLICATIONS 0 CITATIONS

SEE PROFILE

\section{Josef Prijotomo}

Institut Teknologi Sepuluh Nopember

14 PUBLICATIONS 0 CITATIONS

SEE PROFILE 


\title{
Sustainability is Important Part of the Identity in the Dimension of Regionalism Architecture
}

\author{
Maria I Hidayatun ${ }^{1, a}$, Josef Prijotomo ${ }^{2, b}$ and Murni Rachmawati ${ }^{2, c}$ \\ ${ }^{1}$ Department of Architecture, Petra Christian University Surabaya, Student in Post Graduate \\ Department of Architecture, Institut Sepuluh Nopember Surabaya \\ ${ }^{2}$ Department of Architecture, Institut Sepuluh Nopember Surabaya \\ ahidayatun.maria75@gmail.com, 'Jospri@indo.net, 'murnitoni@indo.net
}

Keywords: sustainability, identity, regionalism, architecture.

\begin{abstract}
The objectives of this study are to find that sustainable is important part of the identity in the dimention of regionalism Architecture. By conducting a study of the relationship between sustainable architecture with identity dimensions of regionalism in architecture, will get clarity that sustainability in architecture is an essential part to determine the identity of the architectural regionalism. In particular the identity of the architectural regionalism in Indonesia. This paper will discuss the various works of architecture in Indonesia, which shows the relationship between Identity and sustainability in the dimensions of regionalism architecture. Used a discriptive method with narative as analysis technique, to explain how the relationship between sustainability, identity and regionalism arschitecture to support the sustainable architecture. This study is a library research, so it used some documents data in the form of papers and photographs or images either documented directly or processed by other parties such as the results of research. The results of this study are a concept of sustainability as an important part in maintaining the architectural identity in dimensional regionalism architecture.
\end{abstract}

\section{Introduction}

Since more than two decades the issue of sustainability is a very interesting topic due to the physical condition of natural and disturbed environments. In line with this question of identity is also a topic in various discussions. Meanwhile in the world of architectural thinking of the work of architecture that can reflect local potential by reviewing the potential of the region, has been started since the mid-20th century it is constantly discussed and debated in the meeting that discusses the architectural design and becomes a new approach that is Regionalism architecture. Of the three things mentioned above this study tried to find a link between the three, because it has the same basic issue that rests on the environment, nature and culture.Oleh karena itu perlu dipahami terlebih dulu pengertian tentang identitas, sustainabilitas dan sustainable serta regionalisme. which is can be explain, as follows:

Identity. The term of 'identity', as defined in the Oxford English Dictionary [1], as the state of being very like or the same as something or somebody, or the state of being closely involved with a part of something. Identity is an element of a set which, if combined with another element by a specified binary operation, leaves that element unchanged

In architecture terms, identity cannot be separated from the features and character of a building. Identity will show where the building was produced and by whom the building was presented. Identity is closely related to topography, cultural, material and architects who handle it.

Architecture that was built by people would reflect the knowledge level of the people, in accordance with local natural resources, which includes state topography, availability of building materials and the culture in place. While the architecture produced by an architect would demonstrate the knowledge, how and the depth of appreciation to the building results. 
Sustainable and Sustainability. Sustainable architecture is architecture that seeks to minimize the negative environmental impact of buildings by efficiency and moderation in the use of materials, energy, and development space. Sustainable architecture uses a conscious approach to energy and ecological conservation in the design of the built environment [2].

As a working definition, sustainability can be defined as the practice of maintaining processes of productivity indefinitely natural or human made by replacing resources used with resources of equal or greater value without degrading or endangering natural biotic systems [3]. According to $\mathrm{M}$. Hasna, sustainability is a function of social, economic, technological and ecological themes [4]

Sustainability is based on a simple principle: Everything that we need for our survival and wellbeing depends, either directly or indirectly, on our natural environment. Sustainability creates and maintains the conditions under which humans and nature can exist in productive harmony, that permit fulfilling the social, economic and other requirements of present and future generations.

Sustainability is important to making sure that we have and will continue to have, the water, materials, and resources to protect human health and our environment.

The term "sustainability" in relation to architecture has so far been mostly considered through the lens of building technology and its transformations. Going beyond the technical sphere of "green" design, invention and expertise, some scholars are starting to position architecture within a much broader cultural framework of the human interrelationship with nature. Adopting this framework allows tracing a rich history of cultural debates about our relationship to nature and the environment, from the point of view of different historical and geographical contexts [5].

Regionalism. In international relations, regionalism is the expression of a common sense of identity and purpose combined with the creation and implementation of institutions that express a particular identity and shape collective action within a geographical region. Regionalism is one of the three constituents of the international commercial system (along with multilateralism and unilateralism) [6]. Joseph Nye defined an international region "as a limited number of states linked by a geographical relationship and by a degree of mutual interdependence", and (international) regionalism as "the formation of interstate associations or groupings on the basis of regions"[7]

In Architecture, Regionalism is an architectural development that has great attention to regional characteristics, is closely related to local culture, climate and technology at the time, as well as fusion of the old with the new one and hope the resulting building are timeless.

\section{Methodology}

This study is a qualitative research that believes the reality and complex meaning, subjective and seeks to express specifically oriented to the exploration, discovery and inductive logic. In the writing of this research used descriptive method with narative as analysis technique, because the data base on facts and also empirical event. Descriptive method is means as a procedure how to solve the problem.

This study is a library research, so it used some documents data in the form of papers and photographs or images either documented directly or processed by other parties such as the results of research.

So how to explain that sustainability be an important part to show the architectural identity in the dimension of regionalism architecture can be described in the narrative by using some examples.

\section{Results and Discussion}

The results of the analysis conducted in the narrative in the discussion, it was found that in order to find an identity in architecture Regionalism dimensions, sustainability is an important part. Referring to the main characteristic of architectural identity which includes the relationship with the context (environment and natural), material, form and shape, it is closely related to the core of sustainability, as described as follows: 'Sustainability creates and maintains the conditions under which humans and nature can exist in productive harmony'. 
Thus it is clear how the relationship between sustainability and identity in architecture regionalism dimension. This can be explained in the discussion through several empirical fact that has been carried out by the perpetrators of the architecture, both contemporary architecture, which shows the work of regionalism and architecture created by the people.

\section{Dimension of Regionalism Architecture}

Dimensions in regionalism architecture can be viewed from several points of view based on the viewpoint of the regionalism in general i.e., have the same historical experience, having linkage / cooperation, solve problems together, which is essentially three dimensions are interrelated and cannot be separated each other [8]

In the discussions, dimension of Regionalism architecture is closely related to regional characteristics, which includes of climate, topography and technology at the time and local culture. This is reflected in the architecture that is created, either in the past or in the present and cannot be separated from the function of the building that has a clear character. It can be explained as follows; Fig.1. Show that topography, climate and technology was closely related regional characteristic
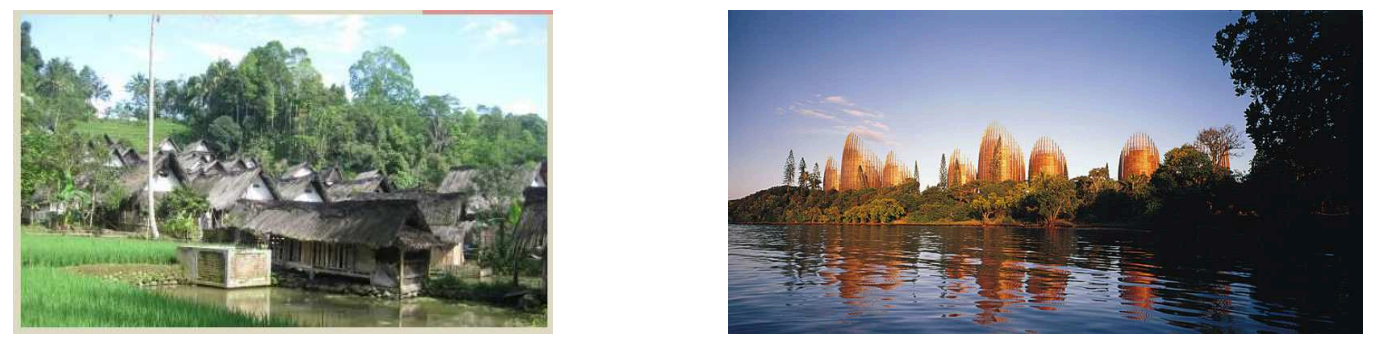

Figure 1, Topography, climate and technology was closely related regional characteristic

\section{Identity in the dimension of regionalism architecture}

As described above: In architecture terms, identity cannot be separated from the features and character of a building. Identity will show where the building was produced and by whom the building was presented. Identity is closely related to topography, cultural, material and architects who handle it. So in the discussions, that identity was very closely related with regional characteristics, that means topography, material and cultural, and also reflected in the building characteristics. Thus, the identity is a major part of the dimensions of regionalism architecture. Fig.2. show that material and cultural was influence to the building, the left one is the representative form from the right one, and the form is not exactly same of both
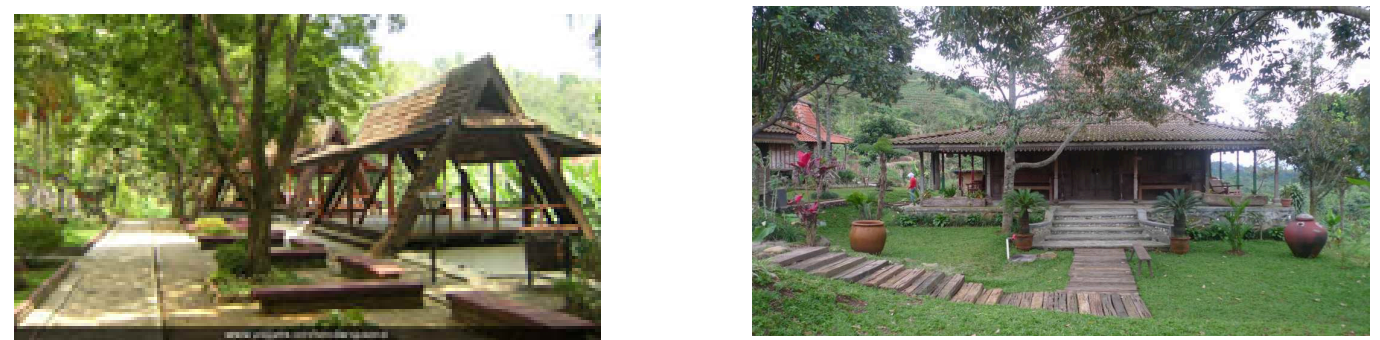

Figure 2, Material and cultural was influence to the building, the left one is the representative form from the right one, and the form is not exactly same of both

\section{Sustainability as an important part of identity}

Sustainability is based on a simple principle: Everything that we need for our survival and wellbeing depends, either directly or indirectly, on our natural environment. The term "sustainability" in relation to architecture has so far been mostly considered through the lens of building technology and its transformations. In the discussion, identity has a permanent nature, as described above permanence is supported by both natural environment and cultural, such as the natural topography, material and cultural includes views and habits. All of this is contained in the sustainable criteria. 
So the nature of sustainability is an important part in recognizing the identity. It can be explain as follows

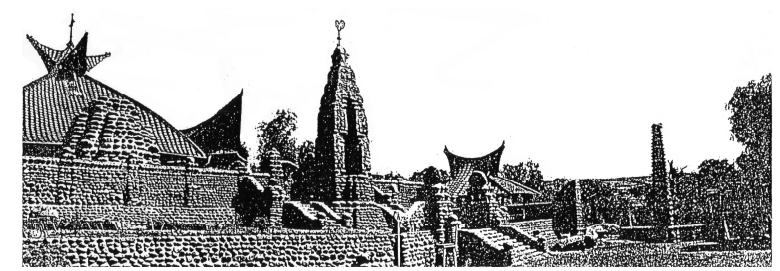

Figure 3, A nature material that shows the building sustainability

From the above discussion, it is clear that the sustainability it's very closely and is important part of the identity in architecture, and the dimension of regionalism architecture cannot be separated with the identity, so identity have a sustainable characteristic because it's permanent value and identity also is the main core in the dimension of regionalism architecture.

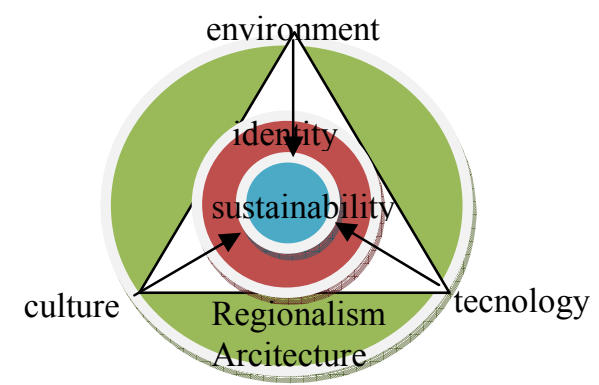

Figure 4, Diagram of sustainability is important part of identity in dimension of regionalism architecture

\section{Summary}

The results of this study are a concept of sustainability as an important part in maintaining the architectural identity in dimensional regionalism architecture. Therefore, there are 3 important points that must be considered which are:

1. The core of the dimensions of regionalism is identity.

2. Identity is permanent

3. As permanent so it should be sustainable in order to preserve the architectural.

Sustainability is part of dimension of architectural regionalism, so there are other dimensions that can be explored further with respect to architectural regionalism in accordance with the issues that developed at the time.

\section{References}

[1] Crowther, 1995, Oxford English Dictionary

[2] "Sustainable Architecture and Simulation Modelling", Dublin Institute of Technology

[3] Melvin K. Hendrix, Sustainable Backyard Polyculture: Designing for ecological resiliency Smashwords ebook edition. 2014.

[4] Hasna, A. M. (2007). "Dimensions of sustainability". Journal of Engineering for Sustainable Development: Energy, Environment, and Health 2 (1): 47-57. doi:10.3992/2166-2517-1.2.47.

[5] McGrath, Brian (2013). Urban Design Ecologies: AD Reader. John Wiley \& Sons, Inc. p. 220237. ISBN 978-0-470-97405-6.

[6] Ethier, Wilfred J. (September 1998). "The International Commercial System". Essays in International Commercial System (Princeton University - Department of Economics) (210): 1-32.

[7] Nye, Joseph (1968). "Introduction". International Regionalism: Readings edited by Joseph Nye. Little, Brown and Company - Boston.

[8] Stubbs, Richard (2011). Routledge Handbook of Asian Regionalism, Routledge, New York. 
Advances in Green Science, Engineering and Built Environment

10.4028/www.scientific.net/AMM.747

Sustainability is Important Part of the Identity in the Dimension of Regionalism Architecture 10.4028/www.scientific.net/AMM.747.145 